\title{
Yiqi Huoxue Recipe alleviates intervertebral disc degeneration by suppressing interleukin-17, nucleus pulposus cell apoptosis and promoting SOX9/ $\beta$-catenin pathway
}

\author{
Zhijia MA ${ }^{1 *}$, Jingwen ZHOU ${ }^{2 *}$, Hong JIANG ${ }^{1}$, Pengfei $\mathrm{YU}^{1}$, Feng DAI ${ }^{1}$, Jintao LIU ${ }^{1 *}$
}

\begin{abstract}
This study aimed to explore the effects of Yiqi Huoxue Recipe (YQHXF) on the pathological changes, Th-17 lymphocyte infiltration, nucleus pulposus cell apoptosis, and the expression of extracellular matrix related proteins in degenerative intervertebral disc of rats. Thirty SD rats were randomly divided into 5 groups (Sham, Model, Low YQHXF, Medium YQHXF, and High YQHXF). In this paper, the annulus fibrosus was broken and arranged disorderly, nucleus pulposus cells apoptosis was increased, and the intervertebral discs were infiltrated by a large number of inflammatory cells in model group rats. However, YQHXF treatment group significantly attenuated these effects. Annulus fibrosus puncture caused increase in Th-17 lymphocyte infiltration and inflammatory factors in the model group, however, those effects were inhibited by YQHXF intervention. YQHXF treatment significantly reduced nucleus pulposus cell apoptosis, which was increased in the model group. The down-regulation of SOX-9 phosphorylation, type II collagen, BMP-2 and the up-regulation of $\beta$-catenin, MMP-3, MMP-13 and ADAMTS5 were found in the model group compared with sham group. However, those changes were significantly attenuated by YQHXF treatment. YQHXF could alleviate intervertebral disc degeneration in rats by reducing Th-17 lymphocyte infiltration, inhibiting nucleus pulposus cell apoptosis and promoting SOX-9/ $\beta$-catenin-mediated ECM synthesis
\end{abstract}

Keywords: Yiqi Huoxue Recipe; intervertebral disc degeneration; interleukin-17; nucleus pulposus cell.

Practical Application: YQHXF improves IVDD through modulating inflammation, apoptosis, and ECM.

\section{Introduction}

At present, it is generally believed that the fundamental pathological change of low back pain is intervertebral disc degeneration (IVDD) (Adams et al., 2010; Vergroesen et al., 2015). Improving IVDD is an important research direction in the prevention and treatment of low back pain. Inflammatory factors play an important role in the progression of IVDD, some studies have indicated that the expression of inflammatory factors were increased in degenerative lumbar disc (Johnson et al., 2015; Risbud \& Shapiro, 2014; Wang et al., 2020). Overexpression of inflammatory factors can destroy the balance of extracellular matrix (ECM) metabolize, promote the expression of proteolytic enzymes, induce apoptosis of nucleus pulposus cells, and induce IVDD (Risbud \& Shapiro, 2014). Chitosan/poly- $\gamma$-glutamic acid nanocomplexes (pro-inflammatory) induced upregulation of IL$1 \beta, \mathrm{IL}-6, \mathrm{COX} 2$ and nucleus pulposus injury, increase of CD4+ T cells in the blood and lymph nodes in a rat IVDD model. However, soluble diclofenac (anti-inflammatory) increased collagen type 2 content and number of nucleus pulposus cells, and promoted M2 macrophages (MHCII+) (Cunha et al., 2020). ECM is mainly composed of collagen and proteoglycan (McKee et al., 2019). During the progression of IVDD, nucleus pulposus structure changes, type II collagen in nucleus pulposus changes to type I collagen, which causes nucleus pulposus fibrosis (Urits et al.,
2019). Kluba et al. (2005) found that the expression of type II collagen gene in IVDD group was significantly lower than that in non-IVDD group, and negatively correlated with the grade of IVDD. The metabolism of ECM is affected by the regulation factors of synthesis and degradation respectively. The regulatory factors of synthesis include bone morphogenetic proteins (BMPs), tissue inhibitors of metalloproteinases (TIMP), and transcription factor SOX9 (SRY related high mobility group box 9) (Li et al., 2018; Zhang et al., 2006). Degradation regulators, including various cytokines (such as IL-1 $\beta$ and TNF- $\alpha$ ), promote the degradation of ECM by regulating matrix metalloproteinases (MMPs) and aggrecanase (ADAMTS) (Wang et al., 2017; Zhang et al., 2019). It has shown that SOX9 was lowly expressed in IVDD and played a key role in the progression of IVDD (Gruber et al., 2005). Transfection of BMPs and SOX9 could promote the expression of type 2 collagen in nucleus pulposus cells, which improved IVDD (Ren et al., 2015). These indicated that SOX9 could be used as a therapeutic target for IVDD.

The clinical treatment of IVDD mainly include drug therapy and physical therapy. nonsteroidal anti-inflammatory drugs, diuretic and detumescence drugs, neurotrophic drugs and so on are often used to treat IVDD (Isa et al., 2015; Liu et al., 2019; Wu et al., 2020a). Recent studies have shown that Traditional 
Chinese Medicine (TCM) treatment of IVDD is through multiple pathways or targets, rather than simple anti-inflammatory (Zhu et al., 2020). Moreover, TCM treatment showed the advantages of low side effects (Zhu et al., 2020). "Fufangqishe-Pill" (containing astragalus membranaceus, Ligusticum chuanxiong, musk, etc.) could improve the degeneration of lumbar intervertebral disc in rats by participating in the inhibition of multi matrix degradation (Liang et al., 2010a). Muscone could down-regulate the expression of IL- $1 \beta$, iNOS, TNF- $\alpha$, COX- 2 mRNA in intervertebral disc mice, and which protected cartilaginous endplate and delayed the occurrence of degeneration (Liang et al., 2010b). TCM treatment in IVDD has got considerable research attention.

Yiqi Huoxue recipe (YQHXR) is a kind of Chinese herbal compound, which consists of membranous milkvetch root (20 $\mathrm{g})$, semen brassicae $(6 \mathrm{~g})$, angelica sinensis (10 g), papaya (10 $\mathrm{g})$, the root of fangji $(10 \mathrm{~g})$, earthworm (15 g) and Ligusticum wallichii $(15 \mathrm{~g})$. Astragalus polysaccharides can promote the transcription of IL-2 gene in traumatic mice, thus correcting the low cellular immune function after trauma (Li et al., 2020). Tetrandrine, the main effective component of the root of fangji, possessed obvious inhibitory effect on cellular and humoral immunity, and also showed strong inhibitory effect on IL- $1 \beta$ and TNF- $\alpha$ levels produced by monocytes and macrophages (Ma et al., 2016; Seow et al., 1992). Tetramethylpyrazine, as the main chemical component of Ligusticum wallichii, could reduce the expression of type 1 collagen, type 3 collagen and a-SMA, inhibit the proliferation of fibroblasts and induce apoptosis (Wu et al., 2020b). However, the effect and mechanism of YQHXR on IVDD have not been reported. Therefore, the main purpose of this study was to evaluate whether YQHXR could improve IVDD, and investigated the underlying mechanism.

\section{Materials and methods}

\subsection{Animals}

Sprague Dawley (SD) rats ( $\mathrm{n}=30,8-9$ weeks, 200-250 g) were purchased from Shanghai Lab. Animal Research Center. All rats were reared at a constant temperature $\left(20 \pm 2{ }^{\circ} \mathrm{C}\right)$, maintained $30-50 \%$ humidity, and kept in a $12 \mathrm{~h}$ day-night light cycle. Feeding, drinking and other activities of rats were kept sterile. All animal experiments were performed in accordance with the guide for the care and use of laboratory animals of Suzhou Hospital of Traditional Chinese Medicine and approved by the animal ethics committee of Suzhou Hospital of Traditional Chinese Medicine.

\subsection{Preparation of YQHXF}

YQHXF consists of membranous milkvetch root $(20 \mathrm{~g})$, semen brassicae (6 g), angelica sinensis (10 g), papaya (10 g), the root of fangji $(10 \mathrm{~g})$, earthworm $(15 \mathrm{~g})$ and Ligusticum wallichii (15 g). YQHXF can be purchased in Suzhou Hospital of Traditional Chinese Medicine. All ingredients are made into $1000 \mathrm{~mL}$ suspension using deionized sterile water, which is concentrated to $200 \mathrm{~mL}$ using low flame, filtered with 100 mesh screen, and stored in vacuum at $4{ }^{\circ} \mathrm{C}$.

\subsection{Experimental design}

30 SD rats were randomly divided into five groups: sham group (Sham, $n=6$ ), model group (Model, $n=6$ ), low dose YQHXF group (L-YQHXF, $n=6$ ), medium dose YQHXF group (M-YQHXF, $n=6$ ), and high dose YQHXF group (H-YQHXF, $\mathrm{n}=6$ ). The rats were anesthetized by intraperitoneal injection of $15 \mathrm{~mL} / \mathrm{kg}$ pentobarbital (3\%), and the operation was performed until the desired anesthetic effect was achieved. The rats were fixed on the operating table in prone position, and then the back of the rats was depilated and disinfected. In the sham operation group, only skin incision and suture were performed along spinous process of back. In the model control group and YQHXF experimental group, the posterior median incision was performed along spinous process of back, the exposed L3/4 intervertebral disc was punctured into $3.0 \mathrm{~mm}$ using a 21 -gauge needle, and the needle was rotated $360^{\circ}$ along the axis twice and maintained for $30 \mathrm{~s}$. These accelerated degeneration of intervertebral disc. Following that, each layer of tissue was sutured in turn, and the rats were treated with intramuscular injection of penicillin to resist infection. YQHXF experimental group was given intragastric administration 1 weeks after modeling. The dosage of L-YQHXF, M-YQHXF and H-YQHXF groups were $0.7,1.4$ and $2.8 \mathrm{~g} / \mathrm{kg} . \mathrm{d}$, respectively. The sham group and model group were given the same volume of $0.9 \%$ normal saline. The rats were euthanized with high concentration of pentobarbital at 8 weeks after operation.

\subsection{Histological staining}

After euthanasia, the intervertebral discs were separated and fixed for 24 hours with $4 \%$ paraformaldehyde, and then made into $4 \mu \mathrm{m}$ paraffin sections. The slices were dewaxed for $5 \mathrm{~min}$ with xylene, soaked for $5 \mathrm{~min}$ with alcohol $(100 \%, 95 \%, 85 \%$, and $75 \%$ alcohol), and then dyed for 5 min with hematoxylin dye.

For hematoxylin-eosin (HE) staining, the slices were differentiated for 50 s with $1 \%$ hydrochloric acid ethanol, and re-stained for $2 \mathrm{~min}$ with $1 \%$ eosin. After gradient ethanol $(75 \%$, $85 \%, 95 \%$, and $100 \%$ alcohol) dehydration, slices were sealed with neutral resin. Five random areas of each slice were observed and photographed using a light microscope (200 X magnifications, Olympus, Tokyo, Japan).

For masson staining, the slices were differentiated for $1 \mathrm{~min}$ with molybdophosphoric acid separation solution, and re-stained for $5 \mathrm{~min}$ with aniline blue staining, washed with absolute ethanol, and then sealed with neutral resin. Five random areas of each slice were observed and photographed using a light microscope (200 X magnifications, Olympus, Tokyo, Japan).

\subsection{Western blot}

Intervertebral disc tissues were ground into homogenate, and then tissues protein was extracted with RIPA reagent. The protein concentration of each group was detected with BCA kit. $25 \mu \mathrm{g}$ protein/Lane was separated by $10 \%$ SDS-PAGE, and then transferred to PVDF membrane. The members were sealed for $2 \mathrm{~h}$ with $5 \%$ skimmed milk powder at room temperature, and then incubated overnight at $4{ }^{\circ} \mathrm{C}$ with the corresponding primary antibody [SOX9 (1:1000, ab182579, Abcam), p-SOX9 (1:1000, 
ab59252, Abcam), Collagen II (1:1000, ab188570, Abcam), BMP2 (1:1000, ab14933, Abcam), MMP-3 (1:1000, ab52915, Abcam), MMP-13 (1:1000, ab51072, Abcam), ADAMTS5 (1:1000, ab41037, Abcam), $\beta$-catenin (1:1000, ab223075, Abcam)]. The members were incubated for $1 \mathrm{~h}$ at room temperature with the second antibody [Goat Anti-Rabbit IgG H\&L (1:5000, ab96899, Abcam) or Goat Anti-Mouse IgG H\&L (1:5000, ab96879, Abcam)]. The protein bonds were visualized using chemiluminescent reagents (Beyotime) in a gel image analysis system (Bio-Rad, USA). GAPDH was used as internal reference.

\subsection{Flow cytometry}

Peripheral blood monocytes were collected and adjusted to $1 \times 10^{10} / \mathrm{L}$. The cells were cultured in RPMI-1640 medium containing $10 \%$ fetal bovine serum, $2.5 \times 10^{-7} \mathrm{~g} / \mathrm{L}$ phorbol ester, $1 \times 10^{-3} \mathrm{~g} / \mathrm{L}$ ionomycin and $1 \times 10^{-2} \mathrm{~g} / \mathrm{L}$ brefeldin $\mathrm{A}$ for $5 \mathrm{~h}$ at $37^{\circ} \mathrm{C}$ and $5 \% \mathrm{CO}_{2}$. The cells were collected and resuspended in $1 \times 10^{6} / 50 \mu \mathrm{L}$ PBS, mixed with pre-cooled anti-PE-Cy5 CD4, and then incubated at room temperature for $20 \mathrm{~min}$. After washed twice with PBS, the cells were resuspended and incubated at $4{ }^{\circ} \mathrm{C}$ for $30 \mathrm{~min}$ with fixation/per-meabilization buffer (FcMACS, Nanjing, Jiangsu, China). After washed twice with PBS, the cells were mixed with anti-PE-IL-17, and then incubated at room temperature for 30 minutes. Following that, flow cytometry was performed in an Attune NXT Acoustic Focusing cytometer (ThermoFisher, Waltham, Ma, USA) and the data was analyzed with Flowjo software (Tree star, Ashland, OR, USA).

\subsection{Immunofluorescence assay}

Cryosection was carried out for the disc tissues. The sections were restored to room temperature, and then fixed and ruptured the membrane for 10 minutes with ice-acetone. The sections were sealed for $30 \mathrm{~min}$ with $3 \%$ bovine serum protein at $37^{\circ} \mathrm{C}$. After washed for 3 times with PBS, and the sections were incubated overnight at $4{ }^{\circ} \mathrm{C}$ with corresponding primary antibody [CD4 (dilution 1:50, ab51312, Abcam Inc., Cambridge, MA, USA) and IL-17A (dilution 1:400, sc-7927; Santa Cruz Biotechnology, Santa Cruz, CA, USA). After washed for 3 times with PBS, the sections were incubated for $60 \mathrm{~min}$ at room temperature with second antibody [Cy3-conjugated IgG (division 1:50, Invitrogen, Paisley, UK) and fluorescein isothiocyanate (FITC)-conjugated IgG (dilution 1:250, sc-3839, US). After washed for 3 times with PBS, the sections were incubated for 15 minutes at room temperature with DAPI, and then sealed. Five random fields were photographed in each slice using a Leica TCS SP5 microscope (Leica Microsystems, Wetzlar, Germany). The number of $\mathrm{CD} 4^{+} / \mathrm{IL}-17^{+}$cells (Th17 cells) was calculated.

\subsection{TUNEL}

Apoptosis of nucleus pulposus cells was detected by TUNEL. The sections were dewaxed for 5 min with xylene, soaked for 5 min with alcohol (100\%, 95\%, 85\%, and 75\% alcohol), and then treated for $30 \mathrm{~min}$ with proteinase $\mathrm{K}$. The sections were incubated for $1 \mathrm{~h}$ at $37^{\circ} \mathrm{C}$ with $50 \mu \mathrm{l}$ of TUNEL reaction mixture, and then incubated for $30 \mathrm{~min}$ at $37^{\circ} \mathrm{C}$ and $50 \mu \mathrm{L}$ of converter
POD. Following that, DAPI was used for nuclear staining, and gradient alcohol dehydration, xylene transparency, and neutral resin sealing were performed. Apoptotic cells were observed and photographed using a fluorescence microscope (Leica Microsystems, Wetzlar, Germany).

\subsection{Reverse transcription-polymerase chain reaction (RT-PCR) assay}

Total RNA was extracted using Trizol reagent in intervertebral disc tissue. The cDNA was obtained by first strand cDNA synthesis supermax Kit (TRANS). The reaction conditions were $42{ }^{\circ} \mathrm{C}$ for $15 \mathrm{~min}$ and $85^{\circ} \mathrm{C}$ for $5 \mathrm{~s}$. RT-PCR was performed using SYBR Green PCR MasterMix (Roche) in an abi7900 imaging system (UVP, LLC, Portland, California, USA). The reaction conditions were $95^{\circ} \mathrm{C}$ denaturation for $60 \mathrm{~s}$, and then 37 cycles were carried out: $95{ }^{\circ} \mathrm{C} 5 \mathrm{~s}, 55^{\circ} \mathrm{C}$ 120 s, $72{ }^{\circ} \mathrm{C} 180$ s. GAPDH was used as normalization. Data were analyzed using $2^{-\Delta \Delta C T}$ method. The primer sequences are shown at Table 1.

\subsection{ELISA}

The levels of IL-1 $\beta$, TNF- $\alpha$ and IL-10 in the serum of peripheral blood and the supernatant of intervertebral disc tissue homogenate were detected by ELISA kit (Nanjing Jiancheng Bioengineering Institute, China), and the experimental operation was strictly performed according with the instructions.

\subsection{Statistical analysis}

The data were analyzed by SPSS 20.0 software (IBM Corp., Armonk, NY, USA), and the experimental data were expressed by mean \pm SD. Univariate analysis of variance followed the Tukey method was used for comparison among $\geq 3$ groups. $\mathrm{P}<0.05$ was indicated as statistically significant. We repeated each experiment was repeated three times.

Table 1. List of primers for RT-PCR analysis.

\begin{tabular}{|c|c|}
\hline The Primer & Sequence 5'-3' \\
\hline SOX9 & $\begin{array}{l}\text { Forward: 5'-TGCAGGAGGAGAAGAGAAGG-3' } \\
\text { Reverse: 5'-GTGGCCAGTTCACAGCTGC-3' }\end{array}$ \\
\hline Collagen 2 & $\begin{array}{l}\text { Forward: 5'-GCTCGCACCTGCAGAGACCTG-3' } \\
\text { Reverse: 5'-GTCCACACCGAATT CCTGCTCG-3' }\end{array}$ \\
\hline BMP2 & $\begin{array}{l}\text { Forward: 5'- } \\
\text { TCATAAAACCTGCAACAGCCAACTCG-3' } \\
\text { Reverse: 5'- GCTGTACTAGCGACACCCAC-3' }\end{array}$ \\
\hline MMP13 & $\begin{array}{l}\text { Forward: 5'-CCGAGGAGAAACAATGATCT-3' } \\
\text { Reverse: 5'-GCCTGTATCCTCAAAGTGAA-3' }\end{array}$ \\
\hline MMP-3 & $\begin{array}{l}\text { Forward: 5'-TCGTTGCTGCTCATGAAATTG-3' } \\
\text { Reverse: 5'-GCTTCAGTGTTGGCTGAGTGAA-3' }\end{array}$ \\
\hline ADAMTS5 & $\begin{array}{l}\text { Forward: 5'-GTCCAAATGCACTTCAGCCA-3' } \\
\text { Reverse: 5'-GGTGGCATCGTAGGTCTGTC-3' }\end{array}$ \\
\hline$\beta$-catenin & $\begin{array}{l}\text { Forward: 5'-AGGAATGAAGGTGTGGCGACA-3' } \\
\text { Reverse: 5'-TGGCAGCCCATCAACTGGAT-3' }\end{array}$ \\
\hline GAPDH & $\begin{array}{l}\text { Forward: 5'-ACCCCAGCAAGGACACTGAGCAAG-3' } \\
\text { Reverse: } \\
\text { 5'-GGCCCCTCCTGTTATTATTATGGGGGT-3' }\end{array}$ \\
\hline
\end{tabular}




\section{Results}

\subsection{YQHXF attenuated the progression of IVDD}

The effect of YQHXF on IVDD was studied by HE staining and Masson staining (Figure 1A and 1B). The results showed that the arrangement of nucleus pulposus cells was normal, there was no obvious inflammatory cell infiltration, and the cartilage was smooth in the sham group. However, in the model group, IVD was infiltrated by a large number of inflammatory cells, fibrous ring was disorderly arranged and ruptured, nucleus pulposus cells was significantly decreased in compare with that in sham group. However, in YQHXF group, the arrangement of nucleus pulposus cells tended to be orderly, the decrease of nucleus pulposus cells was significantly inhibited, the arrangement of annulus fibrosus was gradually uniform, the rupture site was reduced, and the infiltration of inflammatory cells was reduced with the increase of YQHXF-treatment concentration. These results indicated that YQHXF could effectively alleviate the progression of IVDD.

\subsection{YQHXF inhibited Th17 cell infiltration in degenerative intervertebral discs}

Pathological studies showed that there were extensive inflammatory cells infiltrating into the degenerative IVD, so we measured the number of Th17 lymphocytes in the degenerative IVD and serum. IL-17 and CD4 antibodies were used to label Th17
A
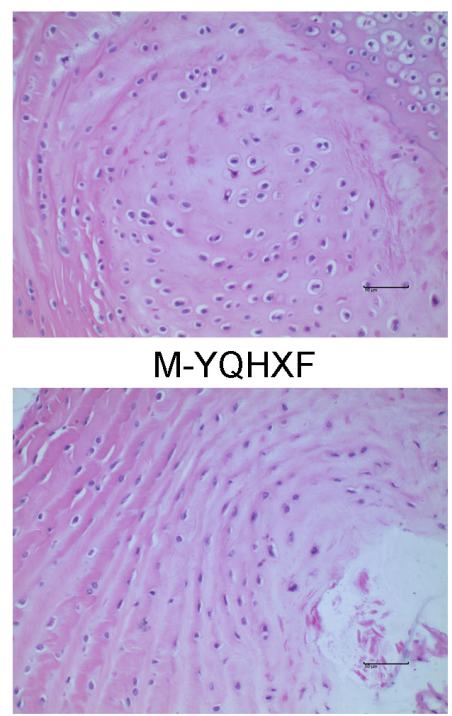

B

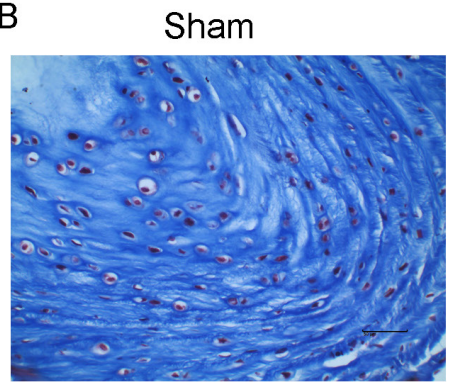

$M-Y Q H X F$

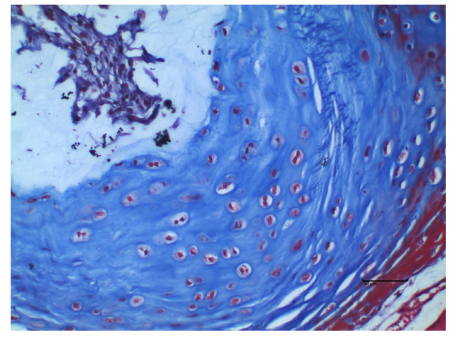

Model

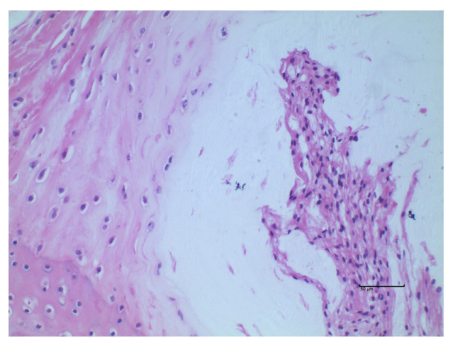

$\mathrm{H}-\mathrm{YQHXF}$



Model

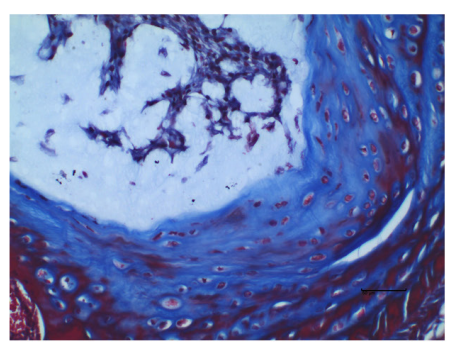

$\mathrm{H}-\mathrm{YQHXF}$

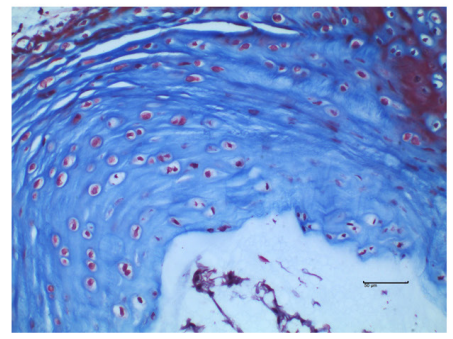

L-YQHXF

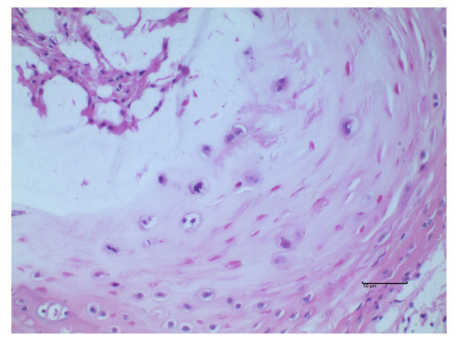$$
\text { . }
$$
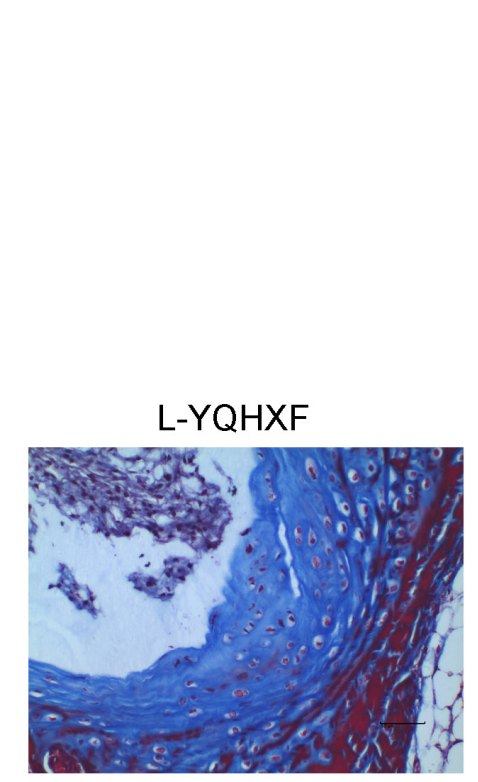

Figure 1. IQHXF improved intervertebral disc degeneration in rat punctured IVDD model. Rats were divided into 5 groups: Sham operation group (Sham group); Co3/4 disc was punctured in IVD (Model group); puncture and intragastric administration of 0.7 g/kg.d YQHXF (L-YQHXF); puncture and intragastric administration of $1.4 \mathrm{~g} / \mathrm{kg} . \mathrm{d}$ YQHXF (M-YQHXF); puncture and intragastric administration of $2.8 \mathrm{~g} / \mathrm{kg}$.d YQHXF (H-YQHXF). (A) Pathological change of IVD was measured by HE staining; (B) Pathological change of IVD was detected by Masson staining. 
to evaluate the number of Th17 in degenerative IVD. Compared with the sham group, the number of IL- $17^{+} \mathrm{CD} 4^{+}$labeled Th17 cells in the model group was significantly increased. Compared with the model group, IL- $17^{+} \mathrm{CD} 4^{+}$labeled Th17 cells in YQHXF groups were significantly reduced (Figure 2). Moreover, the results in serum were similar with that in degenerative IVD (Figure 3). Furthermore, the results showed that the levels of inflammatory factors in serum and IVD tissue in the model group were significantly higher than that in the sham group. However, the expression of inflammatory factors in YQHXF group was inhibited in compare with that in model group (Figure 4A-F). These results suggested that infiltration of Th17 lymphocytes was involved in the progression of IVDD, and YQHXF could inhibit the infiltration of Th17 lymphocytes in the IVDD.
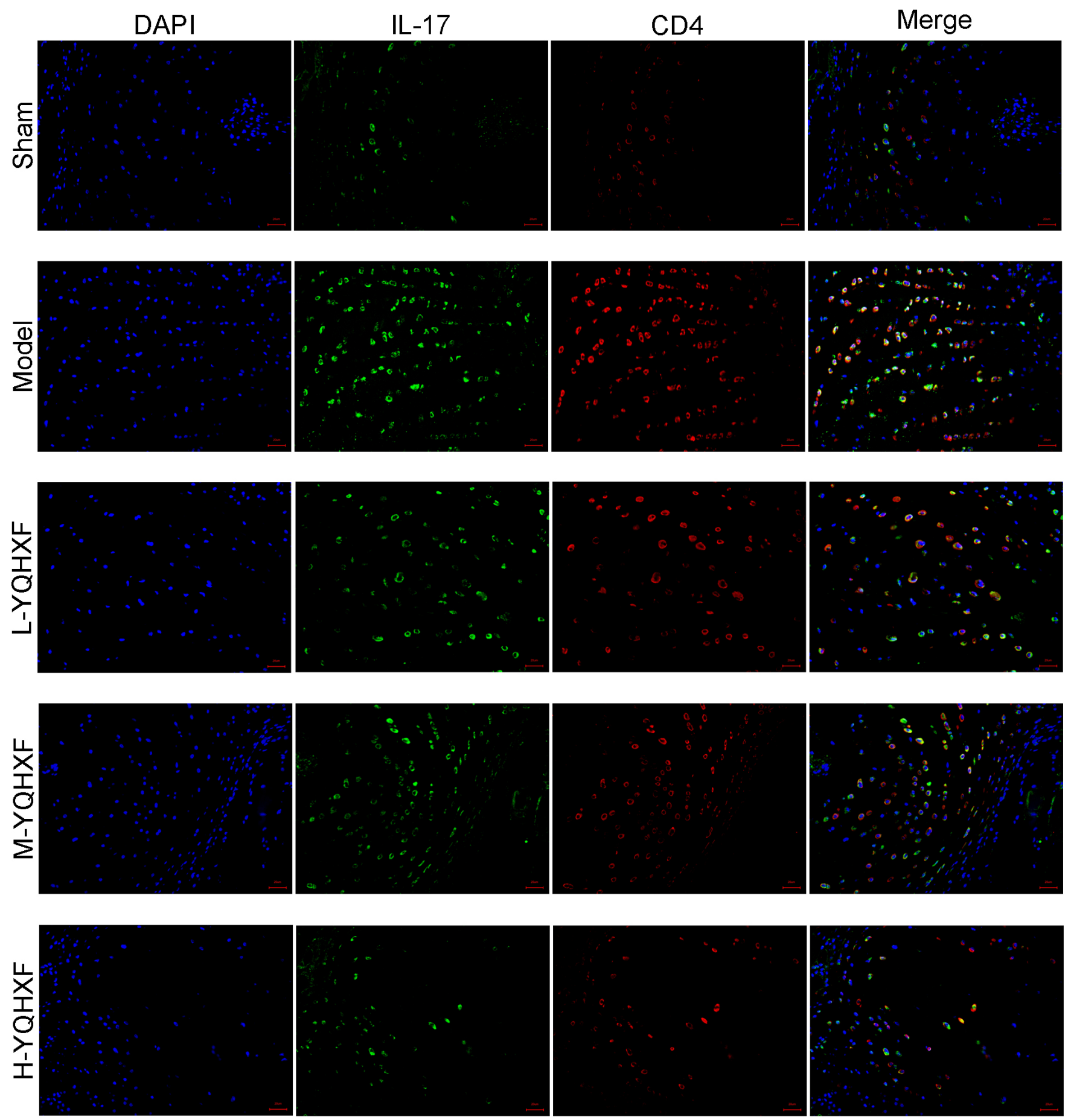

Figure 2. IQHXF reduced IL-17+CD4+ (Th17) cells infiltration in IVD. IL-17 and CD4 marked Th17 cells were detected in IVD by immunofluorescence assay. 

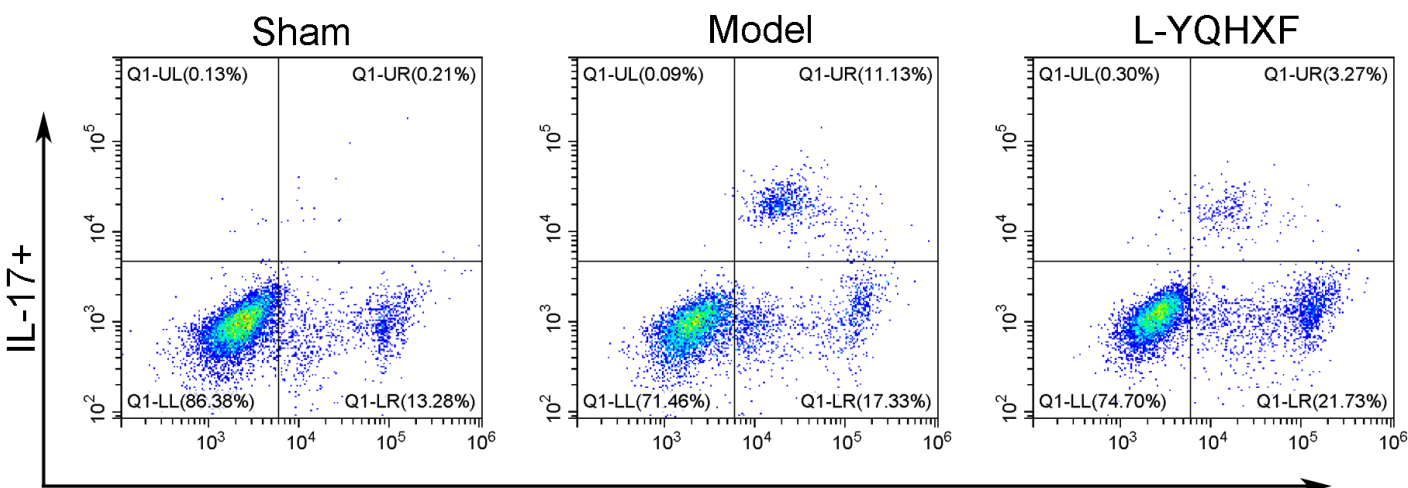

CD4+

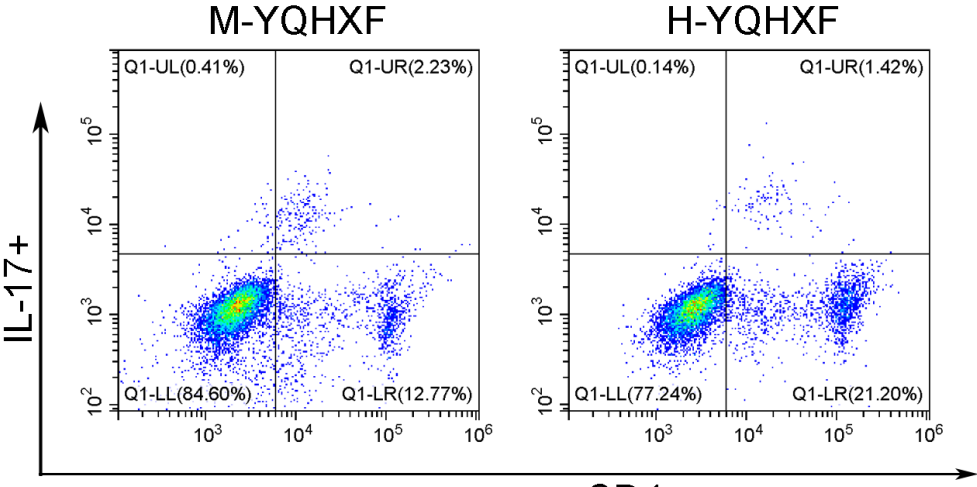

CD4+

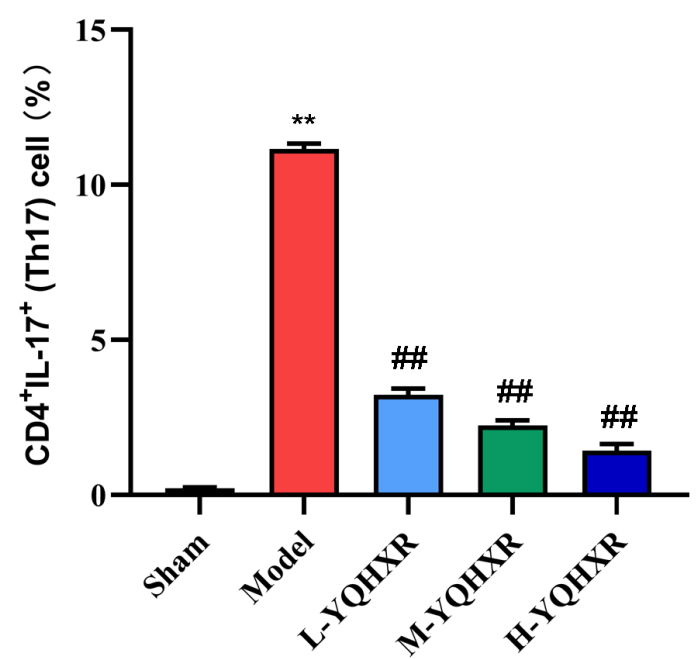

Figure 3. IQHXF decreased IL-17+CD4+ (Th17) cells number in serum. IL-17 and CD4 marked Th17 cells were detected in serum by flow cytometry. ${ }^{* *} \mathrm{P}<0.01$ vs. Sham group, \#\# $<0.01$ vs. Model group.

\subsection{YQHXF inhibited apoptosis of nucleus pulposus cells in degenerative intervertebral discs}

The effect of YQHXF on nucleus pulposus cell apoptosis was detected by TUNEL assay (Figure 5). The results showed that the number of TUNEL stained nucleus pulposus cells in the model group was significantly increased in compare with the sham group, which indicated that the apoptosis of nucleus pulposus cells in the model group was significantly enhanced. However, the number of TUNEL stained nucleus pulposus cells in YQHXF group was significantly reduced in compare with that in model group. These results suggested that YQHXF inhibited the apoptosis of nucleus pulposus cells in IVDD.

\subsection{YQHXF promoted ECM synthesis via SOX9/ß-catenin signaling pathway}

In order to investigate the mechanism of YQHXF improving IVDD, we detected the expression of SOX $9 / \beta$-catenin signaling pathway and ECM related proteins (Figure 6A-H). The results showed that compared with sham group, SOX9 phosphorylation and BMP2 expression were decreased, while 
A

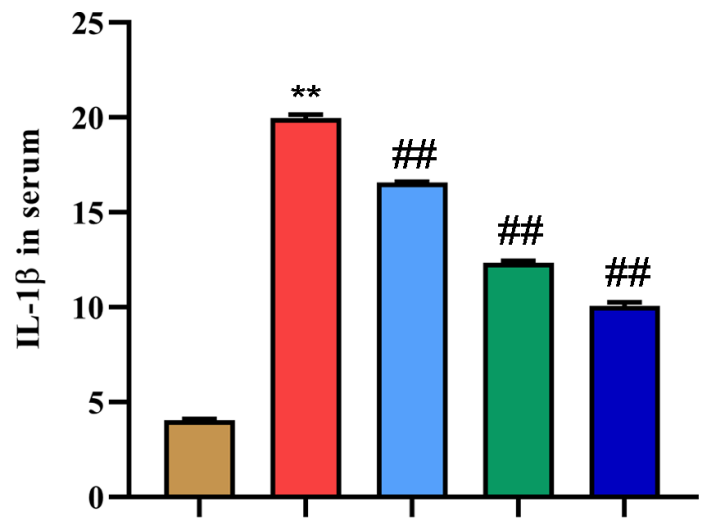

C

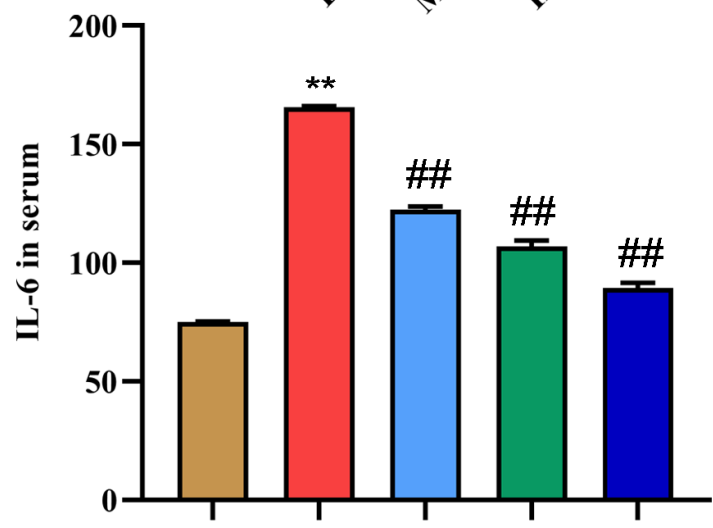

$\mathrm{E}$

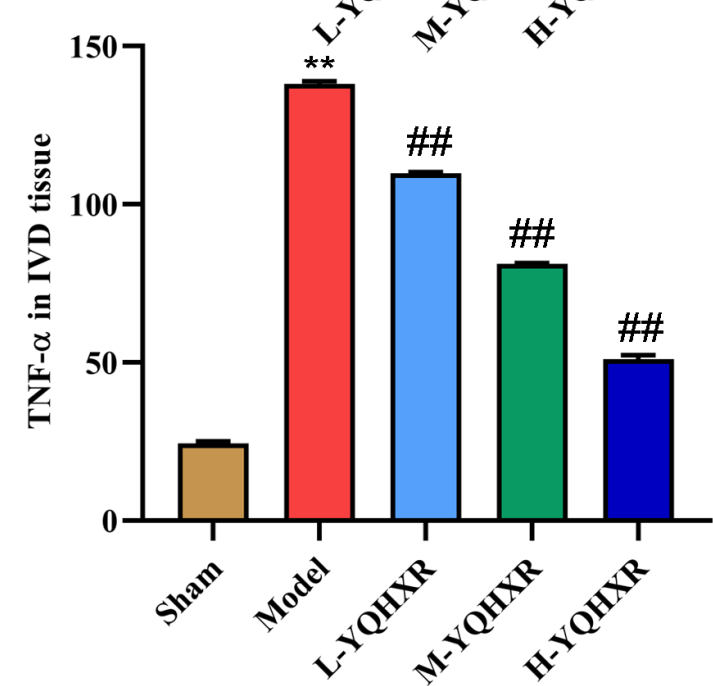

B
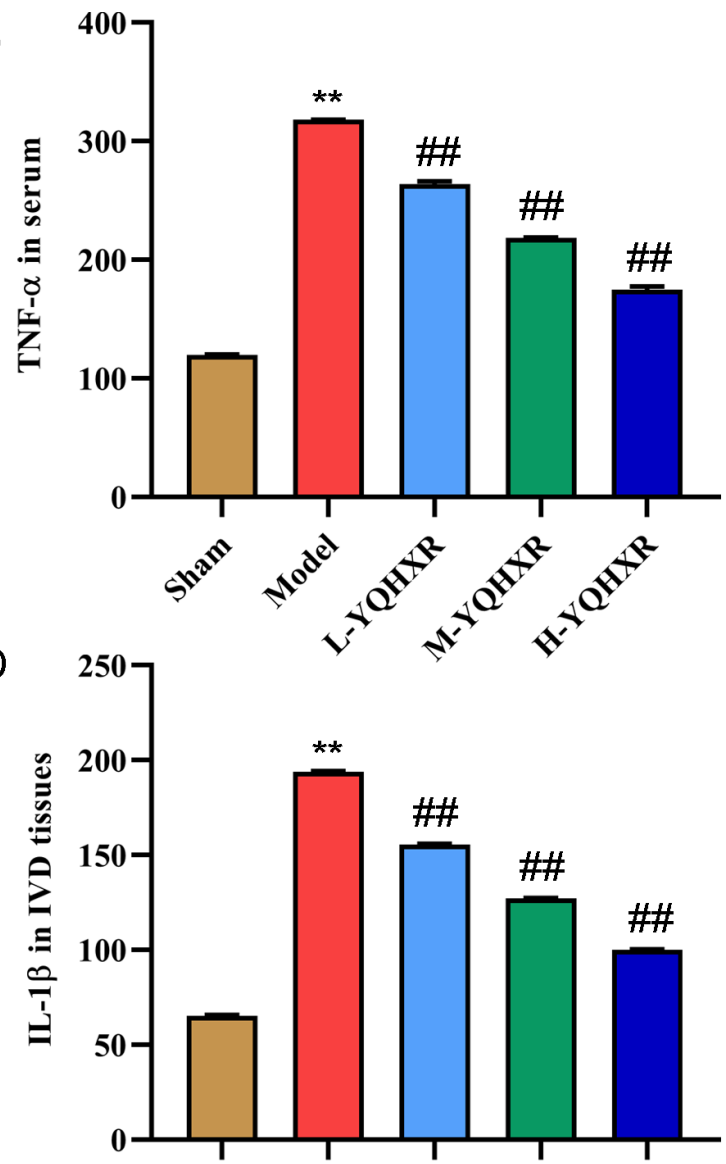

$\mathrm{F}$

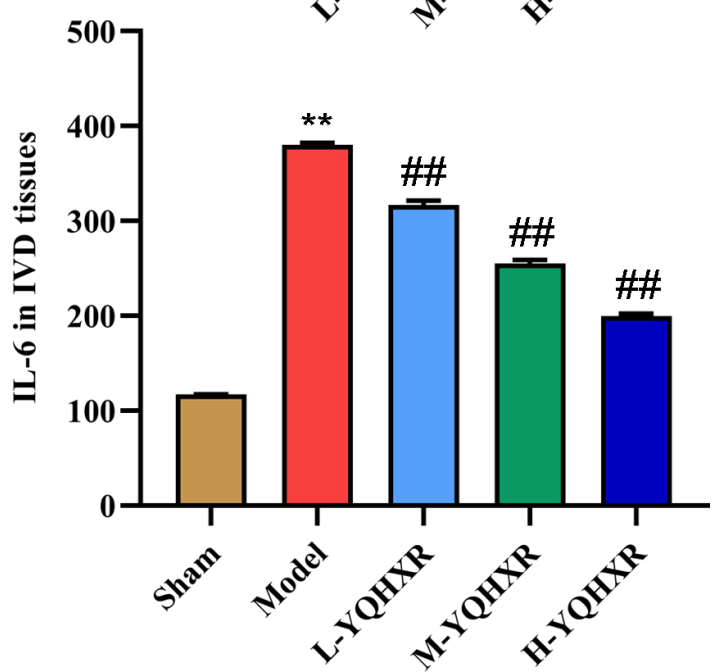

Figure 4. IQHXF inhibited Inflammatory reaction in serum and IVD. (A-C) Inflammatory factors (IL-1 $\beta$, TNF- $\alpha$, and IL-6) in serum were detected by ELISA; (D-F) Inflammatory factors (IL-1 $\beta$, TNF- $\alpha$, and IL-6) in IVD were detected by ELISA. ${ }^{* * P}<0.01$ vs. Sham group, \#\#P $<0.01$ vs. Model group.

$\beta$-catenin expression was increased in model group. In YQHXF group, the phosphorylation of SOX9 and the expression of BMP2 were increased, while the expression of $\beta$-catenin was inhibited. These results indicated that YQHXF promotes the activation of Sox $9 / \beta$-catenin signaling pathway. In addition, the expression of matrix metalloproteinase (MMP-3 and MMP-13), glycoprotein (ADAMTS5), and collagen II were detected. The results showed that the expressions of MMP3, MMP-13 and ADAMTS5 were significantly increased in the model group, while the expression of collagen II was 
significantly decreased in compare with the sham group. In YQHXF group, the expression of MMP-3, MMP-13 and ADAMTS5 were significantly inhibited, while the expression of collagen II was up-regulated. Moreover, the results of
mRNA expression were consistent with those of protein expression (Figure 7A-G). These results demonstrated that YQHXF increased ECM synthesis by activating SOX $9 / \beta$ catenin signaling pathway in IVDD.
DAPI

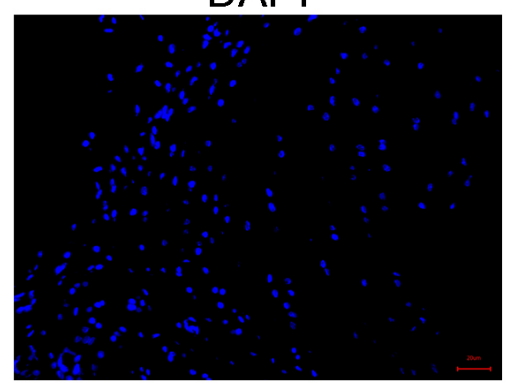

Sham

Model
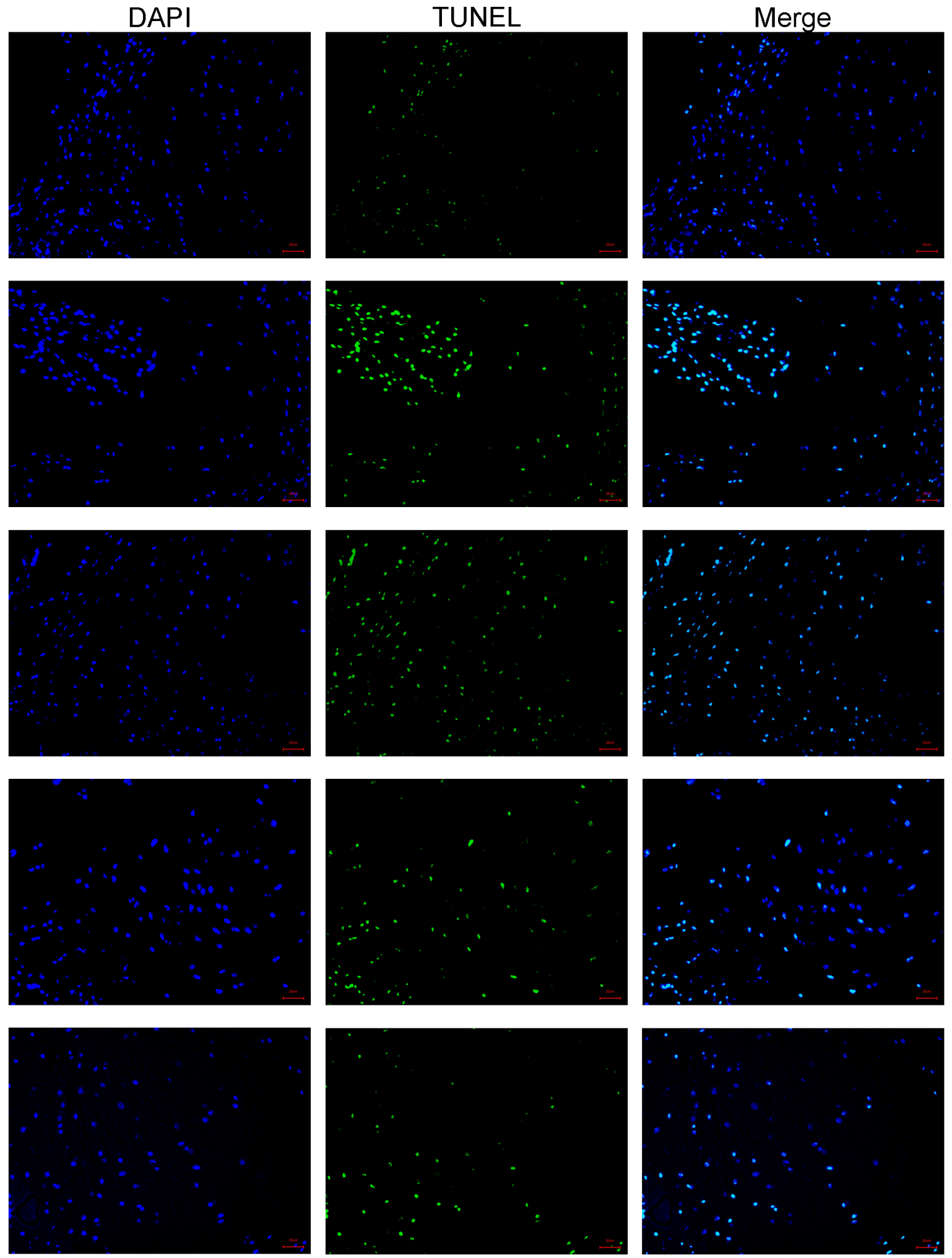

H-YQHXF

M-YQHXF

Figure 5. IQHXF attenuated nucleus pulposus cell apoptosis in IVD. The apoptosis of nucleus pulposus cell in IVD was measured by TUNEL assay. 
A
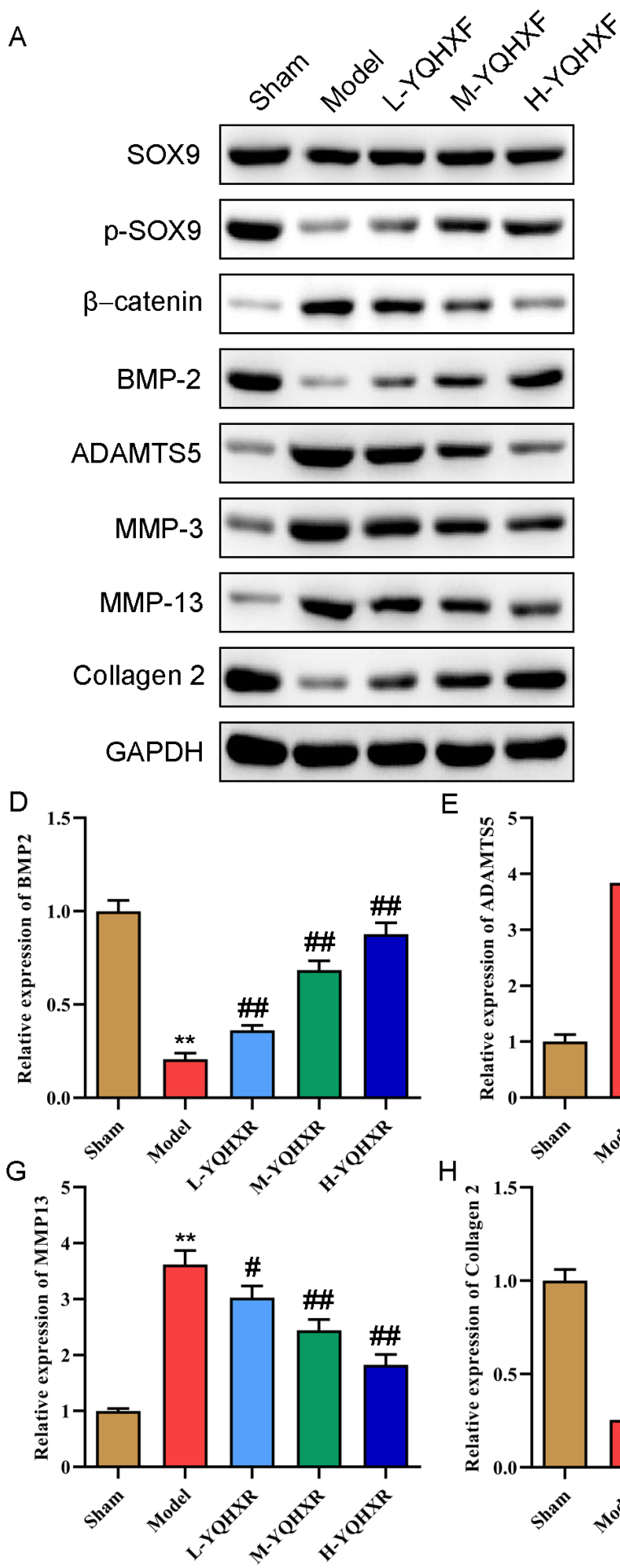

$\mathrm{E}$
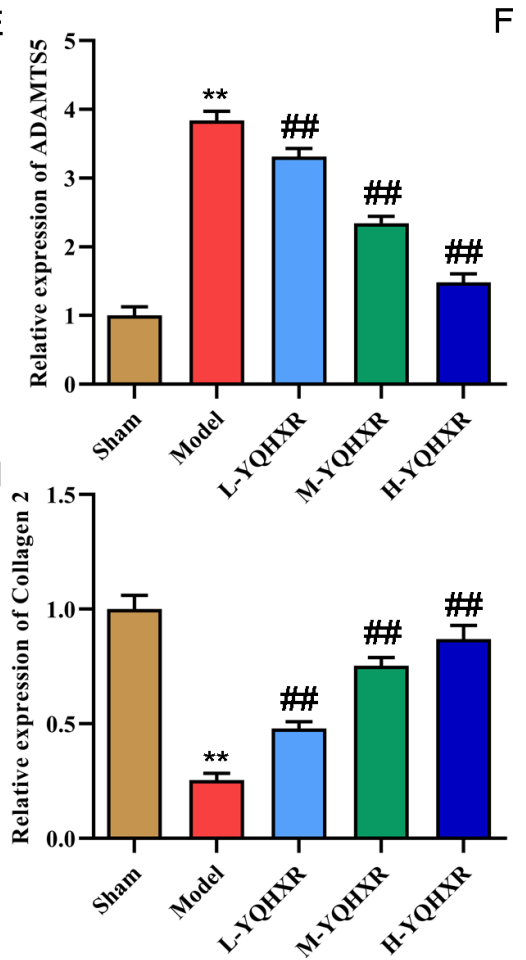

$\mathrm{F}$

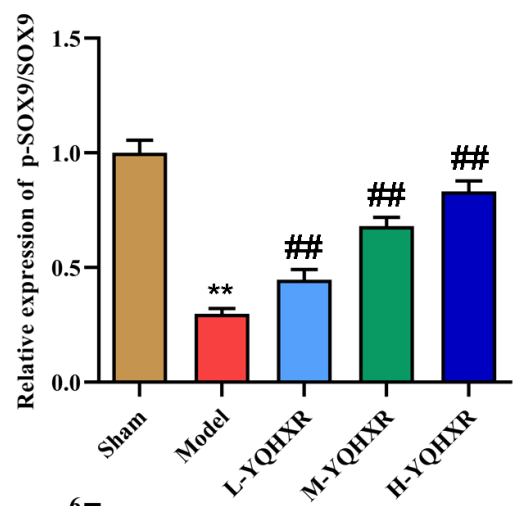

C
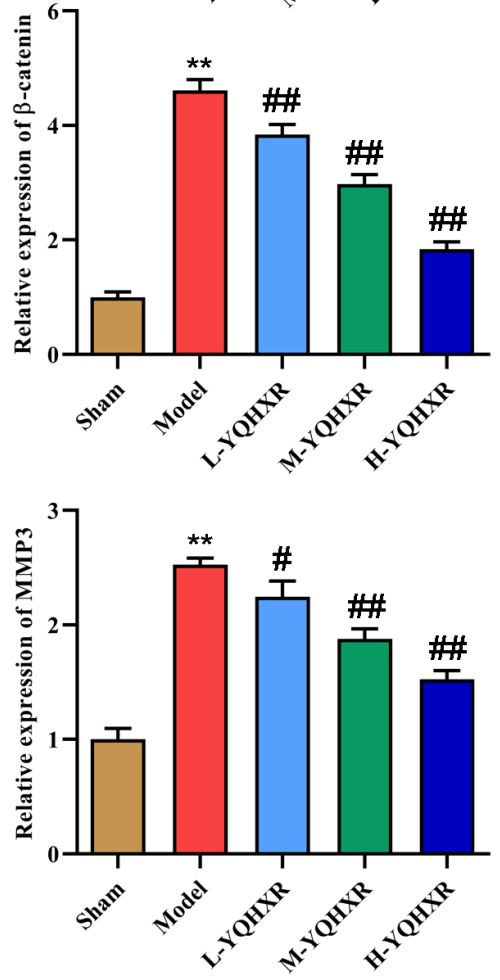

Figure 6. The effect of IQHXF on ECM related protein. (A-H) The SOX9, p-SOX9, $\beta$-catenin, BMP2, ADAMTS5, MMP-3, MMP-13, and Collagen 2 protein expressions were measured by western blot. ${ }^{* *} \mathrm{P}<0.01$ vs. Sham group, $\# \mathrm{P}<0.05$ vs. Model group, $\# \# \mathrm{P}<0.01$ vs. Model group.

\section{Discussion}

In this study, a model of IVDD was constructed by annulus fibrosus puncture as the previous studies (Chen et al., 2020; Zhan et al., 2019; Zhang et al., 2019), and the model was confirmed by observing the pathological changes of IVD. HE and Masson staining results showed that the puncture of annulus fibrosus resulted in the rupture of annulus fibrosus, the decrease of nucleus pulposus cells, and the infiltration of inflammatory cells. These pathological changes were consistent with previous studies (Zhang et al., 2019). 
A

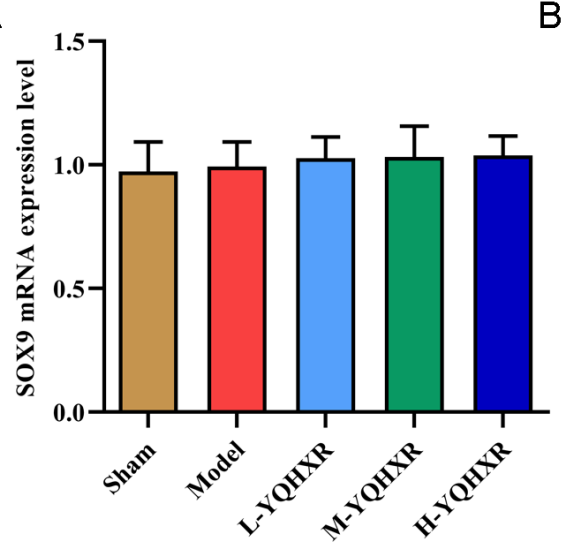

D

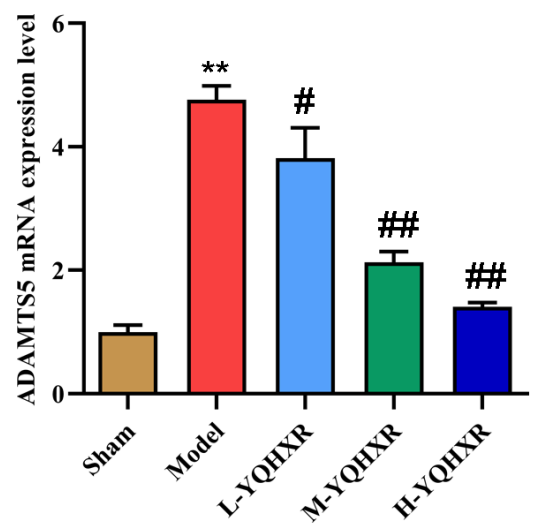

G

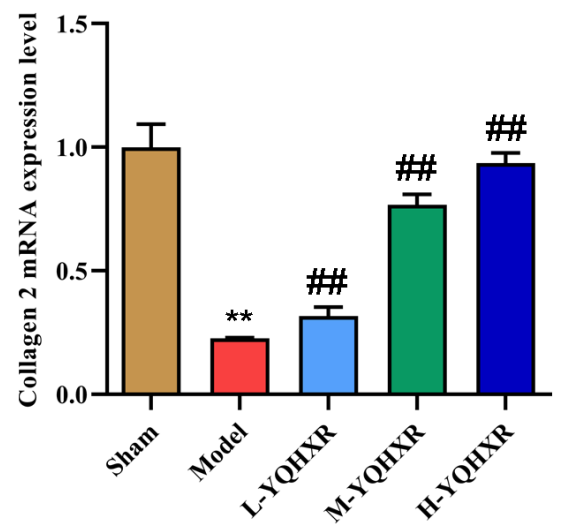

$B$

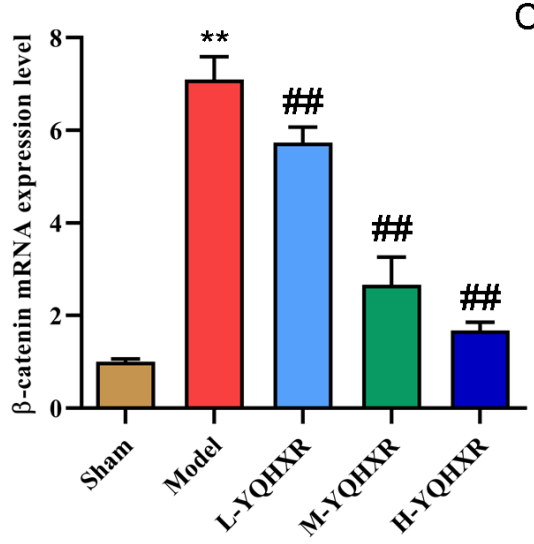

$\mathrm{E}$

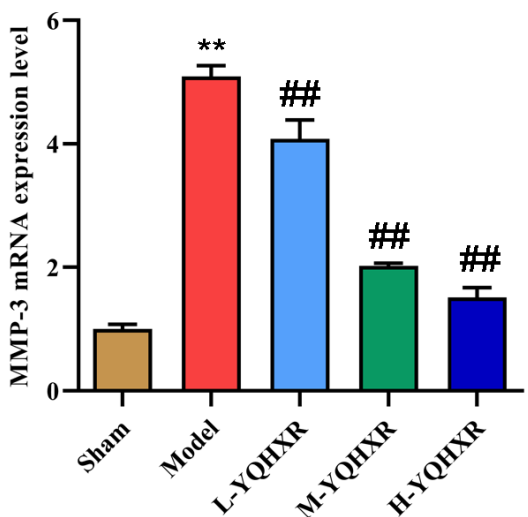

C

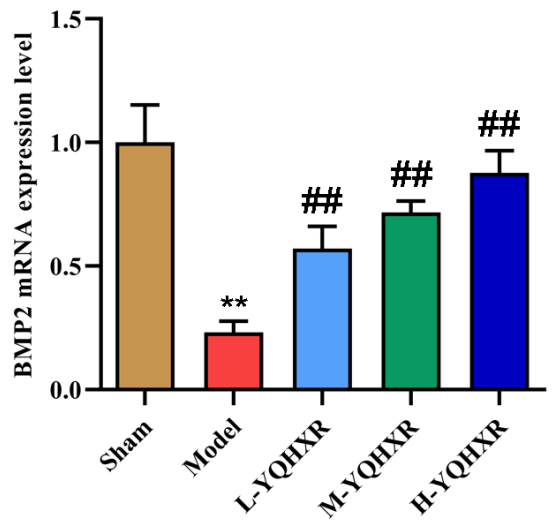

$\mathrm{F}$

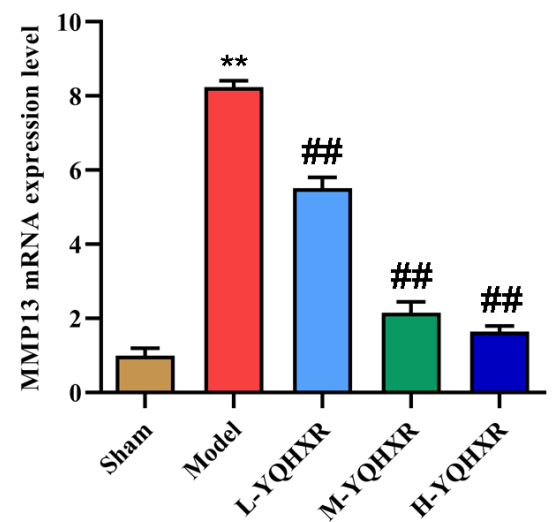

Figure 7. The effect of IQHXF on ECM related mRNA. (A-G) The SOX9, $\beta$-catenin, BMP2, ADAMTS5, MMP-3, MMP-13, and Collagen 2 mRNA expressions were measured by RT-PCR. ${ }^{* *} \mathrm{P}<0.01$ vs. Sham group, $\# \mathrm{P}<0.05$ vs. Model group, $\# \# \mathrm{P}<0.01$ vs. Model group.

In recent years, because the surgical treatment of low back pain could not bring well long-term clinical efficacy to patients, traditional Chinese medicine plays an indispensable role in treatment of IVDD (Kim \& Chung, 2021; Yang et al., 2019; Zhu et al., 2020). Fangji-Duhuo Jisheng decoction could inhibit the degradation of extracellular matrix (ECM) and nucleus pulposus cells apoptosis induced by compress in vitro, and improve the puncture induced IVDD in rats (Liu et al., 2020). Through network pharmacology, it was found that AGE-RAGE, TNF, PI3K, Akt, MAPK, and other signal pathways may be related to Bushen Huoxue Decoction in the treatment of IVDD (Feng et al., 2021). Ge Gen decoction could alleviate cervical spondylosis by inhibiting the expression of PGE2 and COX (Jun et al., 2005). In this study, similarly, YQHXF [membrane milkvetch root $(20 \mathrm{~g})$, semen brassicae (6 g), Angelica sinensis (10 g), papaya (10 g), the root of Fangji $(10 \mathrm{~g})$, earthworm $(15 \mathrm{~g})$ and Ligusticum wallichii $(15 \mathrm{~g})]$ could inhibit the infiltration of Th17 lymphocytes, enhance the apoptosis of nucleus pulposus cells, and degrade ECM in puncture induced IVDD rats. 
Th17 cells are a subset of $\mathrm{CD} 4^{+} \mathrm{T}$ cells independent of Th1 and Th2. A large number of basic studies have shown that Th17 lymphocytes are closely related to a variety of autoimmune and chronic inflammatory diseases (Jun et al., 2005; Miossec \& Kolls, 2012; Yasuda et al., 2019). Th17 cells secrete IL-17, and then stimulate the expression of inflammatory factors such as IL-1, TNF- $\alpha$ and IL- 6 , and a variety of chemokines. Moreover, the chemokines aggravate the inflammatory response by promoting the recruitment and activation of neutrophils and macrophages (Balasa et al., 2020; Tristão et al., 2017; Xu \& Li, 2018). The mRNA and protein expression of IL-17 and TNF- $\alpha$ were higher in patients with ruptured annulus fibrosus than in patients with intact fibrosis (Liu et al., 2016). Down regulation of progranulin could accelerate IVDD by reducing IL-10 and increasing IL-17 in vivo and in vitro (Wang et al., 2018). In this study, the results indicated IL- $17^{+} \mathrm{CD} 4^{+}$positive cells and inflammatory factors (IL- $1 \beta$, TNF- $\alpha$, and IL-10) were increased in degenerative IVD. Moreover, YQHXF could significantly reduce the number of IL- $17^{+} \mathrm{CD} 4^{+}$positive cells in degenerative IVD, and reduce the level of inflammatory factors (IL-1 $\beta$, TNF- $\alpha$, and IL-10).

The normal synthesis of ECM such as proteoglycan and type II collagen play an important role in maintaining the morphology and function of IVD (Chen et al., 2019; Wang et al., 2019a). SOX9 gene is a member of SOX gene family. The smallest COL2A1 gene enhancer was found to be the target gene of SOX9, which indicated that SOX9 gene was involved in the specific activation of COL2A1 in chondrocytes (Smeriglio et al., 2020; Zhang et al., 2015). A large number of studies have shown that the expression of SOX9 can improve IVDD (Ren et al., 2013; Zhang et al., 2021; Zhao et al., 2020). SOX9 gene knockout could cause degradation of ECM in nucleus pulposus cells and annulus fibrosus, induce apoptosis of nucleus pulposus cells, and cause specific changes of transcriptome (including the regulation of extracellular matrix, cytoskeleton and metabolic pathways in nucleus pulposus cells and the regulation of cell cycle and ion transport in annulus fibrosus) (Tsingas et al., 2020). $\beta$-catenin is an important intracellular signal molecule in wnt $/ \beta$-catenin pathway (Valenta et al., 2012). Up-regulation of $\beta$-catenin can combine with $\mathrm{T}$ lymphokines or transcription factors of lymphoenhancer family (TCF/LEF) to activate the expression of Wnt pathway target genes, including bone morphogenetic protein (BMP) 2 and 4, CD44, MMP-7 and MMP-13, interleukin-8 and so on (Doumpas et al., 2019; Wang et al., 2019b). The activation of wnt/ $\beta$-catenin played a positive role in the progression of IVDD (Kondo et al., 2011). Aquaporin 3 could inhibit the degradation of ECM and promote the proliferation of human nucleus pulposus cells, thereby alleviating IVDD, and these effects are partly related to the inhibition of $w n t / \beta$-catenin (Xie et al., 2016). In addition, $\beta$-catenin was inhibited when chondrocytes were infected with adenovirus-mediated SOX-9 gene in vitro (Sinha et al., 2021; Topol et al., 2009), which might be the key way for SOX-9 to promote ECM synthesis. In our study, puncture of annulus fibrosus decreased phosphorylation of Sox-9, BMP 2, and collagen 2, while increased expression of b-catenin, MMP-3, MMP-13, and ADAMTS5 in IVD, and these effects were attenuated by YQHXF intervention. These results suggested that YQHXF might improve IVDD by regulating SOX-9/3-catenin pathway.
There are still some limitations in our research. First of all, we lack clinical experimental data and related cell experiments, which would be our next work. Second, the mechanism of YQHXF regulating nucleus pulposus cell apoptosis and Th-17 cell infiltration is unclear, which need further study.

In conclusion, our study showed that YQHXF could alleviate IVDD by inhibiting nucleus pulposus cell apoptosis, reducing Th-17 cell infiltration, and promoting the SOX-9/ $\beta$-catenin pathway-mediated synthesis of ECM. Our data provided the basis for YQHXF to be widely used in the treatment of IVDD.

\section{Conflict of interest}

The authors declare that they have no competing interests.

\section{Availability of data and material}

The datasets used and/or analyzed during the current study are available from the corresponding author on reasonable request.

\section{Funding}

This study was funded by the project of The Fifth Batch of Gusu Medical talents training Program (Grant number: GSWS2019066 and GSWS2020087), Science and Technology Development Program of Suzhou (Grant number: SYSD2019218), National Natural Science Foundation of Jiangsu (Grant number: BK20201180), National Natural Science Foundation of China (Grant number: 82074467), Science and Technology Development Program of Suzhou (Grant number: SS202084), and Jiangsu Provincial High-level Health Talents "Six Projects" Top Talents Scientific Research Program (Grant number: LGY2020043). The funders had no role in study design, data collection and analysis, decision to publish, or preparation of the manuscript.

\section{References}

Adams, M. A., Stefanakis, M., \& Dolan, P. (2010). Healing of a painful intervertebral disc should not be confused with reversing disc degeneration: implications for physical therapies for discogenic back pain. Clinical Biomechanics, 25(10), 961-971. http://dx.doi. org/10.1016/j.clinbiomech.2010.07.016. PMid:20739107.

Balasa, R., Barcutean, L., Balasa, A., Motataianu, A., Roman-Filip, C., \& Manu, D. (2020). The action of TH17 cells on blood brain barrier in multiple sclerosis and experimental autoimmune encephalomyelitis. Human Immunology, 81(5), 237-243. http://dx.doi.org/10.1016/j. humimm.2020.02.009. PMid:32122685.

Chen, F., Liu, H., Wang, X., Li, Z., Zhang, J., Pei, Y., Zheng, Z., \& Wang, J. (2020). Melatonin activates autophagy via the NF- $\kappa B$ signaling pathway to prevent extracellular matrix degeneration in intervertebral disc. Osteoarthritis and Cartilage, 28(8), 1121-1132. http://dx.doi. org/10.1016/j.joca.2020.05.011. PMid:32470597.

Chen, Y., Wu, Y., Shi, H., Wang, J., Zheng, Z., Chen, J., Chen, X., Zhang, Z., Xu, D., Wang, X., \& Xiao, J. (2019). Melatonin ameliorates intervertebral disc degeneration via the potential mechanisms of mitophagy induction and apoptosis inhibition. Journal of Cellular and Molecular Medicine, 23(3), 2136-2148. http://dx.doi.org/10.1111/ jcmm.14125. PMid:30609271.

Cunha, C., Q Teixeira, G., Ribeiro-Machado, C., Pereira, C., Ferreira, J. R., Molinos, M., Santos, S., Barbosa, M. A., \& Gonçalves, R. (2020). 
Modulation of the in vivo inflammatory response by pro- versus anti-inflammatory intervertebral disc treatments. International Journal of Molecular Sciences, 21(5). http://dx.doi.org/10.3390/ ijms21051730. PMid:32138314.

Doumpas, N., Lampart, F., Robinson, M. D., Lentini, A., Nestor, C. E., Cantù, C., \& Basler, K. (2019). TCF/LEF dependent and independent transcriptional regulation of $\mathrm{Wnt} / \beta$-catenin target genes. The EMBO Journal, 38(2). http://dx.doi.org/10.15252/embj.201798873. PMid:30425074.

Feng, S. H., Xie, F., Yao, H. Y., Wu, G. B., Sun, X. Y., \& Yang, J. (2021). The mechanism of Bushen Huoxue decoction in treating intervertebral disc degeneration based on network pharmacology. Annals of Palliative Medicine, 10(4), 3783-3792. http://dx.doi.org/10.21037/ apm-20-2586. PMid:33752429.

Gruber, H. E., Norton, H. J., Ingram, J. A., \& Hanley, E. N., Jr. (2005). The SOX9 transcription factor in the human disc: decreased immunolocalization with age and disc degeneration. Spine, 30(6), 625-630. http://dx.doi.org/10.1097/01.brs.0000155420.01444.c6. PMid:15770176.

Isa, I. L., Srivastava, A., Tiernan, D., Owens, P., Rooney, P., Dockery, P., \& Pandit, A. (2015). Hyaluronic acid based hydrogels attenuate inflammatory receptors and neurotrophins in interleukin- $1 \beta$ induced inflammation model of nucleus pulposus cells. Biomacromolecules, 16(6), 1714-1725. http://dx.doi.org/10.1021/acs.biomac.5b00168. PMid:25871410.

Johnson, Z. I., Schoepflin, Z. R., Choi, H., Shapiro, I. M., \& Risbud, M. V. (2015). Disc in flames: Roles of TNF- $\alpha$ and IL- $1 \beta$ in intervertebral disc degeneration. European Cells \& Materials, 30, 104-116. http:// dx.doi.org/10.22203/eCM.v030a08. PMid:26388614.

Jun, Z., Fang, S., Huo, H., Qi, Y., Guo, S., Jiang, T., \& Shi, Q. (2005). Effects of Ge Gen Decoction on PGE2 content and COX activity in the degenarated cervical intervertebral discs of rats. Journal of Traditional Chinese Medicine, 25(3), 222-225. PMid:16334730.

Kim, H., \& Chung, W. S. (2021). Traditional Chinese medicine in collaboration with conservative conventional medicine for lumbar herniated intervertebral disc: a protocol for systematic review and meta-analysis. Medicine, 100(16), e25652. http://dx.doi.org/10.1097/ MD.0000000000025652. PMid:33879748.

Kluba, T., Niemeyer, T., Gaissmaier, C., \& Gründer, T. (2005). Human anulus fibrosis and nucleus pulposus cells of the intervertebral disc: effect of degeneration and culture system on cell phenotype. Spine, 30(24), 2743-2748. http://dx.doi.org/10.1097/01.brs.0000192204.89160.6d. PMid:16371897.

Kondo, N., Yuasa, T., Shimono, K., Tung, W., Okabe, T., Yasuhara, R., Pacifici, M., Zhang, Y., Iwamoto, M., \& Enomoto-Iwamoto, M. (2011). Intervertebral disc development is regulated by $\mathrm{Wnt} / \beta$ catenin signaling. Spine, 36(8), E513-E518. http://dx.doi.org/10.1097/ BRS.0b013e3181f52cb5. PMid:21270710.

Li, W., Hu, X., Wang, S., Jiao, Z., Sun, T., Liu, T., \& Song, K. (2020). Characterization and anti-tumor bioactivity of astragalus polysaccharides by immunomodulation. International Journal of Biological Macromolecules, 145, 985-997. http://dx.doi.org/10.1016/j. ijbiomac.2019.09.189. PMid:31669273.

Li, X., Cheng, S., Wu, Y., Ying, J., Wang, C., Wen, T., Bai, X., Ji, W., Wang, D., \& Ruan, D. (2018). Functional self-assembled peptide scaffold inhibits tumor necrosis factor-alpha-induced inflammation and apoptosis in nucleus pulposus cells by suppressing nuclear factor- $\kappa \mathrm{B}$ signaling. Journal of Biomedical Materials Research. Part A, 106(4), 1082-1091. http://dx.doi.org/10.1002/jbm.a.36301. PMid:29164771.

Liang, Q. Q., Xi, Z. J., Bian, Q., Cui, X. J., Li, C. G., Hou, W., Shi, Q., \& Wang, Y. J. (2010a). Herb formula "Fufangqishe-Pill" prevents upright posture-induced intervertebral disc degeneration at the lumbar in rats. Journal of Pharmacological Sciences, 113(1), 23-31. http://dx.doi.org/10.1254/jphs.09231FP. PMid:20472983.

Liang, Q. Q., Zhang, M., Zhou, Q., Shi, Q., \& Wang, Y. J. (2010b). Muscone protects vertebral end-plate degeneration by antiinflammatory property. Clinical Orthopaedics and Related Research, 468(6), 16001610. http://dx.doi.org/10.1007/s11999-009-1079-0. PMid:19763723.

Liu, W., Jin, S., Huang, M., Li, Y., Wang, Z., Wang, P., Zhao, X., Xia, P., \& Feng, J. (2020). Duhuo jisheng decoction suppresses matrix degradation and apoptosis in human nucleus pulposus cells and ameliorates disc degeneration in a rat model. Journal of Ethnopharmacology, 250, 112494. http://dx.doi.org/10.1016/j.jep.2019.112494. PMid:31874213.

Liu, X. G., Hou, H. W., \& Liu, Y. L. (2016). Expression levels of IL-17 and TNF- $\alpha$ in degenerated lumbar intervertebral discs and their correlation. Experimental and Therapeutic Medicine, 11(6), 23332340. http://dx.doi.org/10.3892/etm.2016.3250. PMid:27284317.

Liu, Y., Lin, J., Wu, X., Guo, X., Sun, H., Yu, B., Shen, J., Bai, J., Chen, Z., Yang, H., Geng, D., \& Mao, H. (2019). Aspirin-mediated attenuation of intervertebral disc degeneration by ameliorating reactive oxygen species in vivo and in vitro. Oxidative Medicine and Cellular Longevity, 2019, 7189854. http://dx.doi.org/10.1155/2019/7189854. PMid:31781346.

Ma, H., Yao, L., Pang, L., Li, X., \& Yao, Q. (2016). Tetrandrine ameliorates sevoflurane-induced cognitive impairment via the suppression of inflammation and apoptosis in aged rats. Molecular Medicine Reports, 13(6), 4814-4820. http://dx.doi.org/10.3892/mmr.2016.5132. PMid:27082007.

McKee, T. J., Perlman, G., Morris, M., \& Komarova, S. V. (2019). Extracellular matrix composition of connective tissues: a systematic review and meta-analysis. Scientific Reports, 9(1), 10542. http:// dx.doi.org/10.1038/s41598-019-46896-0. PMid:31332239.

Miossec, P., \& Kolls, J. K. (2012). Targeting IL-17 and TH17 cells in chronic inflammation. Nature Reviews. Drug Discovery, 11(10), 763-776. http://dx.doi.org/10.1038/nrd3794. PMid:23023676.

Ren, S., Liu, Y., Ma, J., Liu, Y., Diao, Z., Yang, D., Zhang, X., Xi, Y., \& $\mathrm{Hu}, \mathrm{Y}$. (2013). Treatment of rabbit intervertebral disc degeneration with co-transfection by adeno-associated virus-mediated SOX 9 and osteogenic protein-1 double genes in vivo. International Journal of Molecular Medicine, 32(5), 1063-1068. http://dx.doi.org/10.3892/ ijmm.2013.1497. PMid:24045878.

Ren, X. F., Diao, Z. Z., Xi, Y. M., Qi, Z. H., Ren, S., Liu, Y. J., Yang, D. L., Zhang, X., \& Yuan, S. L. (2015). Adeno-associated virus-mediated BMP-7 and SOX9 in vitro co-transfection of human degenerative intervertebral disc cells. Genetics and Molecular Research, 14(2), 37363744. http://dx.doi.org/10.4238/2015.April.22.1. PMid:25966142.

Risbud, M. V., \& Shapiro, I. M. (2014). Role of cytokines in intervertebral disc degeneration: pain and disc content. Nature Reviews. Rheumatology, 10(1), 44-56. http://dx.doi.org/10.1038/ nrrheum.2013.160. PMid:24166242.

Seow, W. K., Ferrante, A., Summors, A., \& Thong, Y. H. (1992). Comparative effects of tetrandrine and berbamine on production of the inflammatory cytokines interleukin- 1 and tumor necrosis factor. Life Sciences, 50(8), PL53-PL58. http://dx.doi.org/10.1016/00243205(92)90373-W. PMid:1310515.

Sinha, A., Fan, V. B., Ramakrishnan, A. B., Engelhardt, N., Kennell, J., \& Cadigan, K. M. (2021). Repression of Wnt $/ \beta$-catenin signaling by SOX 9 and Mastermind-like transcriptional coactivator 2. Science Advances, 7(8). http://dx.doi.org/10.1126/sciadv.abe0849. PMid:33597243.

Smeriglio, P., Grandi, F. C., Taylor, S. E. B., Zalc, A., \& Bhutani, N. (2020). TET1 directs chondrogenic differentiation by regulating 
SOX9 dependent activation of Col2a1 and Acan in vitro. JBMR Plus, 4(8), e10383. http://dx.doi.org/10.1002/jbm4.10383. PMid:33134768.

Topol, L., Chen, W., Song, H., Day, T. F., \& Yang, Y. (2009). Sox9 inhibits Wnt signaling by promoting beta-catenin phosphorylation in the nucleus. The Journal of Biological Chemistry, 284(5), 3323-3333. http://dx.doi.org/10.1074/jbc.M808048200. PMid:19047045.

Tristão, F. S. M., Rocha, F. A., Carlos, D., Ketelut-Carneiro, N., Souza, C. O. S., Milanezi, C. M., \& Silva, J. S. (2017). Th17-inducing cytokines IL- 6 and IL-23 are crucial for granuloma formation during experimental paracoccidioidomycosis. Frontiers in Immunology, 8, 949. http://dx.doi.org/10.3389/fimmu.2017.00949. PMid:28871251.

Tsingas, M., Ottone, O. K., Haseeb, A., Barve, R. A., Shapiro, I. M., Lefebvre, V., \& Risbud, M. V. (2020). Sox9 deletion causes severe intervertebral disc degeneration characterized by apoptosis, matrix remodeling, and compartment-specific transcriptomic changes. Matrix Biology, 94, 110-133. http://dx.doi.org/10.1016/j.matbio.2020.09.003. PMid:33027692.

Urits, I., Capuco, A., Sharma, M., Kaye, A. D., Viswanath, O., Cornett, E. M., \& Orhurhu, V. (2019). Stem cell therapies for treatment of discogenic low back pain: a comprehensive review. Current Pain and Headache Reports, 23(9), 65. http://dx.doi.org/10.1007/s11916019-0804-y. PMid:31359164.

Valenta, T., Hausmann, G., \& Basler, K. (2012). The many faces and functions of $\beta$-catenin. The EMBO Journal, 31(12), 2714-2736. http:// dx.doi.org/10.1038/emboj.2012.150. PMid:22617422.

Vergroesen, P. P., Kingma, I., Emanuel, K. S., Hoogendoorn, R. J., Welting, T. J., van Royen, B. J., van Dieën, J. H., \& Smit, T. H. (2015). Mechanics and biology in intervertebral disc degeneration: a vicious circle. Osteoarthritis and Cartilage, 23(7), 1057-1070. http://dx.doi. org/10.1016/j.joca.2015.03.028. PMid:25827971.

Wang, Y., Yu, D., Liu, Z., Zhou, F., Dai, J., Wu, B., Zhou, J., Heng, B. C., Zou, X. H., Ouyang, H., \& Liu, H. (2017). Exosomes from embryonic mesenchymal stem cells alleviate osteoarthritis through balancing synthesis and degradation of cartilage extracellular matrix. Stem Cell Research \& Therapy, 8(1), 189. http://dx.doi.org/10.1186/s13287017-0632-0. PMid:28807034.

Wang, S., Wei, J., Fan, Y., Ding, H., Tian, H., Zhou, X., \& Cheng, L. (2018). Progranulin Is positively associated with intervertebral disc degeneration by interaction with IL-10 and IL-17 through TNF pathways. Inflammation, 41(5), 1852-1863. http://dx.doi.org/10.1007/ s10753-018-0828-1. PMid:29992506.

Wang, J., Liu, X., Sun, B., Du, W., Zheng, Y., \& Sun, Y. (2019a). Upregulated miR-154 promotes ECM degradation in intervertebral disc degeneration. Journal of Cellular Biochemistry, 120(7), 1190011907. http://dx.doi.org/10.1002/jcb.28471. PMid:30825225.

Wang, Z., Zhang, M., Wang, J., \& Ji, H. (2019b). Optimization of peptidomimetics as selective inhibitors for the $\beta$-catenin/T-cell factor protein-protein interaction. Journal of Medicinal Chemistry, 62(7), 3617-3635. http://dx.doi.org/10.1021/acs.jmedchem.9b00147. PMid:30856332.

Wang, Y., Che, M., Xin, J., Zheng, Z., Li, J., \& Zhang, S. (2020). The role of IL- $1 \beta$ and TNF- $\alpha$ in intervertebral disc degeneration. Biomedicine and Pharmacotherapy, 131, 110660. http://dx.doi.org/10.1016/j. biopha.2020.110660. PMid:32853910.

Wu, P. H., Kim, H. S., \& Jang, I. T. (2020a). Intervertebral disc diseases part 2: a review of the current diagnostic and treatment strategies for intervertebral disc disease. International Journal of Molecular Sciences, 21(6), 2135. http://dx.doi.org/10.3390/ijms21062135. PMid:32244936.

Wu, X., Wang, Z., Wu, G., Xu, X., Zhang, J., Li, Y., Zhang, H., \& Guo, S. (2020b). Tetramethylpyrazine induces apoptosis and inhibits proliferation of hypertrophic scar-derived fibroblasts via inhibiting the phosphorylation of AKT. Frontiers in Pharmacology, 11, 602. http://dx.doi.org/10.3389/fphar.2020.00602. PMid:32431617.

Xie, H., Jing, Y., Xia, J., Wang, X., You, C., \& Yan, J. (2016). Aquaporin 3 protects against lumbar intervertebral disc degeneration via the Wnt/ $\beta$-catenin pathway. International Journal of Molecular Medicine, 37(3), 859-864. http://dx.doi.org/10.3892/ijmm.2016.2470. PMid:26820815.

$\mathrm{Xu}$, S. P., \& Li, Y. S. (2018). Fisetin inhibits pristine-induced systemic lupus erythematosus in a murine model through CXCLs regulation. International Journal of Molecular Medicine, 42(6), 3220-3230. http:// dx.doi.org/10.3892/ijmm.2018.3903. PMid:30272314.

Yang, S., Li, L., Zhu, L., Zhang, C., Li, Z., Guo, Y., Nie, Y., \& Luo, Z. (2019). Bu-Shen-Huo-Xue-Fang modulates nucleus pulposus cell proliferation and extracellular matrix remodeling in intervertebral disk degeneration through miR-483 regulation of Wnt pathway. Journal of Cellular Biochemistry, 120(12), 19318-19329. http://dx.doi. org/10.1002/jcb.26760. PMid:29393545.

Yasuda, K., Takeuchi, Y., \& Hirota, K. (2019). The pathogenicity of Th17 cells in autoimmune diseases. Seminars in Immunopathology, 41(3), 283-297. http://dx.doi.org/10.1007/s00281-019-00733-8. PMid:30891627.

Zhan, S., Wang, K., Song, Y., Li, S., Yin, H., Luo, R., Liao, Z., Wu, X., Zhang, Y., \& Yang, C. (2019). Long non-coding RNA HOTAIR modulates intervertebral disc degenerative changes via Wnt/ $\beta$ catenin pathway. Arthritis Research \& Therapy, 21(1), 201. http:// dx.doi.org/10.1186/s13075-019-1986-8. PMid:31481088.

Zhang, S., Song, S., Zhuang, Y., Hu, J., Cui, W., Wang, X., Zhao, Z., Liu, X., \& Sun, Z. (2021). Role of microRNA-15a-5p/Sox9/NF- $\kappa B$ axis in inflammatory factors and apoptosis of murine nucleus pulposus cells in intervertebral disc degeneration. Life Sciences, 277, 119408. http://dx.doi.org/10.1016/j.lfs.2021.119408. PMid:33781831.

Zhang, Y., An, H. S., Thonar, E. J., Chubinskaya, S., He, T. C., \& Phillips, F. M. (2006). Comparative effects of bone morphogenetic proteins and sox9 overexpression on extracellular matrix metabolism of bovine nucleus pulposus cells. Spine, 31(19), 2173-2179. http:// dx.doi.org/10.1097/01.brs.0000232792.66632.d8. PMid:16946650.

Zhang, Y., He, F., Chen, Z., Su, Q., Yan, M., Zhang, Q., Tan, J., Qian, L., \& Han, Y. (2019). Melatonin modulates IL-1 $\beta$-induced extracellular matrix remodeling in human nucleus pulposus cells and attenuates rat intervertebral disc degeneration and inflammation. Aging (Albany NY), 11(22), 10499-10512. http://dx.doi.org/10.18632/aging.102472. PMid:31772145.

Zhang, Y., Li, R., Zhong, Y., Zhang, S., Zhou, L., \& Shang, S. (2015). Fuyuan decoction enhances SOX9 and COL2A1 expression and Smad2/3 phosphorylation in IL-1 $\beta$-activated chondrocytes. EvidenceBased Complementary and Alternative Medicine, 2015, 821947. http:// dx.doi.org/10.1155/2015/821947. PMid:26770254.

Zhao, Z., Li, S., Huang, H., Fang, J., Wei, H., \& Xi, Y. (2020). In vivo delivery of MMP3-shRNA and Sox9 lentivirus cocktail enhances matrix synthesis to prevent lumbar disc degeneration. Advances in Clinical and Experimental Medicine, 29(6), 639-647. http://dx.doi. org/10.17219/acem/121509. PMid:32589824.

Zhu, L., Yu, C., Zhang, X., Yu, Z., Zhan, F., Yu, X., Wang, S., He, F., Han, Y., \& Zhao, H. (2020). The treatment of intervertebral disc degeneration using Traditional Chinese Medicine. Journal of Ethnopharmacology, 263, 113117. http://dx.doi.org/10.1016/j. jep.2020.113117. PMid:32738389. 